J. Dairy Sci. 99:7877-7880

http://dx.doi.org/10.3168/jds.2016-11613

(C) 2016, THE AUTHORS. Published by FASS and Elsevier Inc. on behalf

of the American Dairy Science Association ${ }^{\circledR}$. This is an open access article under

the CC BY-NC-ND license (http://creativecommons.org/licenses/by-nc-nd/3.0/).

\title{
Short communication: Isolation of Shiga toxin-producing Escherichia coli in raw milk and mozzarella cheese in southern Italy
}

\author{
G. Nobili, ${ }^{*}$ I. Franconieri, ${ }^{*}$ M. G. Basanisi, ${ }^{*}$ G. La Bella, ${ }^{*}$ R. Tozzoli, $†$ A. Caprioli, $†$ and G. La Salandra*1 \\ *Istituto Zooprofilattico Sperimentale della Puglia e della Basilicata (IZS PB), Via Manfredonia 20, 71121 Foggia, Italy \\ †EU Reference Laboratory for E. coli, Veterinary Public Health and Food Safety Department, Istituto Superiore di Sanità, Viale Regina Elena 299, \\ 00161 Rome, Italy
}

\begin{abstract}
Shiga toxin-producing Escherichia coli (STEC) are a significant food-borne public health hazard in Europe, where most human infections are associated with 5 serogroups (O157, O26, O103, O145, and O111). In 2015, 95 food and environmental samples were examined for the presence of Shiga toxin genes (stx1 and stx2). The STEC were isolated from 2 raw milk and 1 mozzarella cheese samples that were collected in the period between June and September. To the best of our knowledge, this finding represents the first report of STEC isolation from mozzarella cheese produced in Italy, and it suggests that both the quality of raw milk used to produce mozzarella and the thermal inactivation treatment associated with the curd-stretching step should be carefully monitored.
\end{abstract}

Key words: Shiga-toxigenic Escherichia coli, raw milk and mozzarella cheese, PFGE, real-time PCR

\section{Short Communication}

Shiga toxin-producing Escherichia coli (STEC) can cause human infections ranging from uncomplicated diarrhea to severe diseases as hemorrhagic colitis and life-threatening hemolytic uremic syndrome (HUS; Melton-Celsa et al., 2012). Human STEC infections are acquired through direct or indirect fecal-oral contact with human or animal feces and ruminants have been identified as a major reservoir of STEC (Caprioli et al., 2005). As reported in the literature, contaminated raw milk and raw milk products are among the main risk factors considered STEC vectors (Baylis, 2009), as also reported in several studies in Italy (Trevisani et al.,

Received June 14, 2016.

Accepted July 4, 2016.

${ }^{1}$ Corresponding author: giovanna.lasalandra@izspb.it 2014a). A typical Italian cheese is cow milk mozzarella cheese, mainly manufactured in limited geographical areas of southern Italy using traditional protocols. Apulia is one of the main Italian regions where this food commodity is produced. The main features of the production process include the use of raw milk, natural whey starter cultures, stretching in hot water at $90^{\circ} \mathrm{C}$ (temperature of the curd $58-65^{\circ} \mathrm{C}$ ), and storage at 0 to $4^{\circ} \mathrm{C}$ for $4 \mathrm{~d}$ before consumption as fresh. In Italy, previous experimental studies revealed the STEC contamination in raw milk products, although with a low prevalence (Conedera et al., 2004).

In a recent outbreak in southern Italy, with 22 cases of HUS due to O26 STEC, the infection was related to a suspect contamination of raw milk products or vegetables distributed locally in Apulia region. Given the increase of HUS cases in the Apulia region in recent years, the aim of our study was to report the results of a 1-yr monitoring program and the prevalence of STEC in food and environmental samples and to assess the risk of food contamination with STEC.

In 2015, specifically in the period between June and September, 95 food and environmental samples were sent to Istituto Zooprofilattico Sperimentale della Puglia e della Basilicata (IZS PB), a public veterinary institute that conducts prevention, control, and research activities in animal health and welfare, food safety, and environmental protection. In particular, 32 cheese samples (33.7\%), 6 raw milk samples $(6.3 \%), 27$ specimens of meat and meat products $(28.4 \%), 10$ vegetable samples (10.5\%), 17 samples of water $(17.9 \%)$, and 3 fecal samples were analyzed (3.1\%). The samples were collected from local retail stores and farmers' markets in the Apulia region by the local health services and transferred under refrigerated conditions to the laboratories of IZS PB.

The samples were analyzed according to ISO (2012). The DNA extracts were obtained using PrepSEQ Rapid Spin Sample Preparation Kits (Thermo Fisher 
Scientific, Waltham, MA) according to manufacturer's instructions. The DNA were tested by real-time PCR for the Shiga toxin genes (stx1 and stx2) and eae gene using the technology platform 7500 Fast Real-Time PCR (Applied Biosystems, Thermo Fisher Scientific). The identification of O157, O26, O111, O103, and O145 serotypes was performed following ISO (2012), whereas O104:H4 identification followed the procedure European Union Reference Laboratory for E. coli (2013a) and O45, O55, O91, O113, O121, O128, and O146 serotypes according to European Union Reference Laboratory for E. coli (2013b). In addition, stx gene subtypes were determined according to the protocol described by Scheutz et al. (2012). The STEC isolates provided by European Union Reference Laboratory for E. coli were used as reference strains.

Presumptive positive samples were subjected to the microbiological isolation according to ISO (2012). All strain isolates were tested for susceptibility to selected antimicrobial agents using a disk diffusion method outlined by the Clinical and Laboratory Standards Institute (CLSI, 2012). The antimicrobials assayed are reported in Table 1 . The results were recorded after 24 $\mathrm{h}$ of incubation at $37^{\circ} \mathrm{C}$ and interpreted according to charts supplied with the discs (CLSI, 2012).

The isolates were subjected to molecular typing by pulsed-field gel electrophoresis (PFGE) according to the CDC PulseNet protocol (Ribot et al., 2006) and multilocus sequence typing (MLST) according to the E. coli MLST website (http://mlst.warwick.ac.uk/ mlst/dbs/Ecoli) using 7 housekeeping genes ( $a d k$, fum $C$, gyrB, icd, $m d h$, purA, and recA).

Out of 95 samples analyzed, 7 enrichment cultures (7\%) were positive for stx genes, but STEC strains were isolated from only $3(3 \%)$ of them: 2 from raw milk samples and 1 from mozzarella cheese. The contaminated mozzarella cheese was made from curd purchased from the dairy farm where the 2 STEC-positive raw milk samples had been collected. All isolates were positive for the stx2 gene and negative for the stx1 and eae genes and for all the serogroup-associated genes tested. As reported in the literature (Farrokh et al., 2013), the virulence gene stx2 is the most clinically important Stx type. It has been shown that the probability to develop HUS upon STEC infection is higher when STECproducing Stx2 are involved. In addition, subtyping of stx genes showed the presence of both stx2c and stx2d subtypes, those most commonly associated with severe human disease (Farrokh et al., 2013). The 3 isolates exhibited a multidrug resistance profile characterized by resistance to ampicillin, amoxicillin-clavulanic acid, cephalothin, streptomycin, and tetracycline. These data are in accordance with previous studies (Schroeder et al., 2002), suggesting the use of these drugs has been a key factor in the emergence of antimicrobial-resistant $E$. coli and the risk of transfer the antimicrobial resistance from food animals to humans through the spread of genetic elements. Two isolates were also resistant to ciprofloxacin and 1 to sulfamethoxazole (Table 1).

The genetic relatedness of the 3 STEC strains isolated from raw milk and mozzarella cheese samples was investigated by PFGE, which showed a $100 \%$ similarity (Figure 1). The MLST confirmed the strict correlation of the 3 STEC isolates, which showed the same sequence type (ST1611). This sequence type could be assigned to the phylogenetic group B1 (Doumith et al., 2012). Interestingly, the STEC strain isolated from mozzarella cheese was of the same sequence type, virulence genes profile, and PFGE pattern of the STEC isolates from raw milk samples collected at the farm that had pro-

Table 1. Antimicrobial resistance of 3 Shiga toxin-producing Escherichia coli strains

\begin{tabular}{|c|c|c|c|c|c|c|}
\hline \multirow[b]{2}{*}{ Antibiotic } & \multirow[b]{2}{*}{ Manufacturer ${ }^{1}$} & \multirow[b]{2}{*}{$\begin{array}{c}\text { Concentration } \\
(\mu \mathrm{g})\end{array}$} & \multirow{2}{*}{$\begin{array}{c}\text { Susceptible } \\
\text { breakpoint } \\
(\mathrm{mm})\end{array}$} & \multicolumn{3}{|c|}{ Isolated strains $^{2}$} \\
\hline & & & & $\begin{array}{l}\text { Raw } \\
\text { milk } 1\end{array}$ & $\begin{array}{l}\text { Raw } \\
\text { milk } 2\end{array}$ & $\begin{array}{c}\text { Mozzarella } \\
\text { cheese }\end{array}$ \\
\hline Amoxicillin/clavulanic acid & Liofilchem & $20 / 10$ & $\geq 18$ & $\mathrm{R}$ & $\mathrm{R}$ & $\mathrm{R}$ \\
\hline Ampicillin & Liofilchem & 10 & $\geq 17$ & $\mathrm{R}$ & $\mathrm{R}$ & $\mathrm{R}$ \\
\hline Ceftriaxone & BioLab & 30 & $\overline{\geq} 23$ & $\mathrm{~S}$ & $\mathrm{~S}$ & $\mathrm{~S}$ \\
\hline Cephalothin & Liofilchem & 30 & $\geq 18$ & $\mathrm{R}$ & $\mathrm{R}$ & $\mathrm{R}$ \\
\hline Chloramphenicol & Mast Diagnostics & 30 & $\geq 18$ & $\mathrm{~S}$ & $\mathrm{~S}$ & $\mathrm{~S}$ \\
\hline Ciprofloxacin & BioLab & 5 & $\overline{\geq} 21$ & $\mathrm{R}$ & $\mathrm{S}$ & $\mathrm{R}$ \\
\hline Gentamicin & Liofilchem & 10 & $\geq 15$ & $\mathrm{~S}$ & $\mathrm{~S}$ & $\mathrm{~S}$ \\
\hline Naladixic acid & BioLab & 30 & $\geq 19$ & $\mathrm{~S}$ & $\mathrm{~S}$ & $\mathrm{~S}$ \\
\hline Streptomycin & Liofilchem & 10 & $\geq 15$ & $\mathrm{R}$ & $\mathrm{R}$ & $\mathrm{R}$ \\
\hline Sulfamethoxazole & BioLab & 10 & $\geq 16$ & $\mathrm{~S}$ & $\mathrm{R}$ & $\mathrm{S}$ \\
\hline Tetracycline & Liofilchem & 30 & $\geq 15$ & $\mathrm{R}$ & $\mathrm{R}$ & $\mathrm{R}$ \\
\hline
\end{tabular}

${ }^{1}$ Liofilchem, Roseto degli Abruzzi (Te), Italy; Biolab Inc., Budapest, Hungary; Mast Diagnostics Ltd, Merseyside, UK.

${ }^{2} \mathrm{R}=$ resistant; $\mathrm{S}=$ susceptible. 


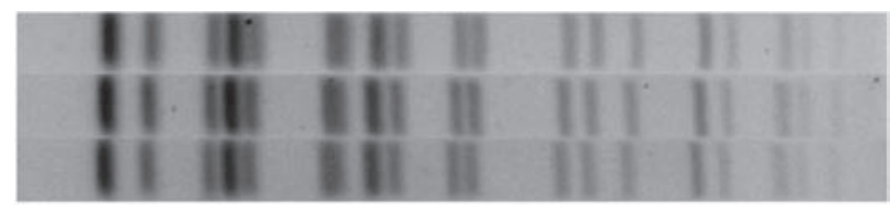

Figure 1. Pulsed-field gel electrophoresis patterns of 3 Shiga toxinproducing Escherichia coli strains with $\mathrm{XbaI}$, isolated from raw milk and mozzarella cheese samples. The figure shows identical pulsed-field gel electrophoresis profiles.

vided the curd to the cheese factory that produced the mozzarella cheese. This finding demonstrates that the STEC contaminating raw milk persisted through the processes of both the curd and the mozzarella cheese production. This observation is particularly interesting, as the curd-stretching step during the mozzarella manufacturing process was performed in water kept at 90 to $95^{\circ} \mathrm{C}$ for a short time. Such temperatures should effectively reduce the number of STEC (Galiero et al., 2005); however, it is probable that the interior curd mass may not have reached a temperature high enough to eliminate the STEC. Moreover, during the transition from milk (liquid) to curds (solid), an increase in the numbers of STEC occurs due to the entrapment of the pathogen in the curds after whey drainage (Farrokh et al., 2013). Studies with artificially contaminated fresh-kneaded curd cheese confirmed that E. coli O157 is capable of surviving during the cheese manufacture process and subsequent ripening and storage periods (Spano et al., 2003; Trevisani et al., 2014b). This has implications on the exposure of consumers to risk of acquiring STEC infections, as the curd-stretching phase must not be too long to avoid loss of fat and soluble proteins (Trevisani et al., 2014b).

To the best of our knowledge, this represents the first report of contamination of mozzarella cheese with STEC in Italy. The occurrence of STEC in raw milk and dairy products represents a significant risk to public health. To preserve the organoleptic properties of mozzarella cheese, it is necessary to use raw milk and it is therefore imperative to ensure that the raw milk used in the manufacture is of the highest bacteriological quality. Thus, adequate control at primary production and by suppliers is necessary. The presence of STEC in raw milk used to produce mozzarella (a farmer's performance objective) and the thermal inactivation time and temperature during the curd-spinning step (a producer's process criterion) should be strictly monitored to ensure that the potential hazards posed by the presence of STEC in cow milk farms are under control. In addition, long-term strategies to ensure the safety of dairy foods should be developed including educational programs to build awareness of the STEC problem among dairy farmers, processors, and consumers.

\section{ACKNOWLEDGMENTS}

The research leading to these results received funding from the Italian Ministry of Health (Rome; RC IZS PB 02/13). The authors acknowledge the staff of Food Microbiology and Veterinary Diagnostic Laboratories from IZS PB (Foggia, Italy) and Antonio Parisi (IZS PB, Putignano, Italy) for technical support.

\section{REFERENCES}

Baylis, C. 2009. Raw milk and raw milk cheeses as vehicles for infection by cerocytotoxin-producing Escherichia coli. Int. J. Dairy Technol. 62:293-307.

Caprioli, A., S. Morabito, H. Brugere, and E. Oswald. 2005. Enterohaemorrhagic Escherichia coli: Emerging issues on virulence and modes of transmission. Vet. Res. 36:289-311.

CLSI. 2012. Performance Standards for Antimicrobial Susceptibility Testing, Twenty-Second Informational Supplement. Vol. 32. Clinical and Laboratory Standards Institute, Wayne, PA.

Conedera, G., P. Dalvit, M. Martini, G. Galiero, M. Gramaglia, E. Goffredo, G. Loffredo, S. Morabito, D. Ottaviani, F. Paterlini, G. Pezzotti, M. Pisanu, P. Semprini, and A. Caprioli. 2004. Verocytotoxin-producing Escherichia coli O157 in minced beef and dairy products in Italy. Int. J. Food Microbiol. 96:67-73.

Doumith, M., M. J. Day, R. Hope, J. Wain, and N. Woodford. 2012. Improved multiplex PCR strategy for rapid assignment of the four major Escherichia coli phylogenetic groups. J. Clin. Microbiol. 50:3108-3110.

European Union Reference Laboratory for E. coli. 2013a. Detection and identification of Verocytotoxin-producing Escherichia coli (VTEC) O104:H4 in food by Real Time PCR. Accessed Jan. 20, 2016. http://www.iss.it/binary/vtec/cont/EU_RL_VTEC_ Method_04_Rev_1.pdf.

European Union Reference Laboratory for E. coli. 2013b. Identification and characterization of Verocytotoxin-producing Escherichia coli (VTEC) by Real Time PCR amplification of the main virulence genes and the genes associated with the serogroups mainly associated with severe human infections. Accessed Jan. 20, 2016. http://www.iss.it/binary/vtec/cont/EU_RL_VTEC_ Method_02_Rev_0.pdf.

Farrokh, C., K. Jordan, F. Auvray, K. Glass, H. Oppegaard, S. Raynaud, D. Thevenot, R. Condron, K. De Reu, A. Govaris, K. Heggum, M. Heyndrickx, J. Hummerjohann, D. Lindasay, S. Miszczyche, S. Moussiegt, K. Verstraete, and O. Cerf. 2013. Review of Shiga-toxin-producing Escherichia coli (STEC) and their significance in dairy production. Int. J. Food Microbiol. 162:190-212.

Galiero, G., G. Conedera, D. Alfano, and A. Caprioli. 2005. Isolation of verocytotoxin-producing Escherichia coli O157 from water buffaloes (Bubalus bubalis) in southern Italy. Vet. Rec. 156:382-383.

ISO. 2012. ISO/TS 13136:2012. Microbiology of food and animal feed - Real-time polymerase chain reaction (PCR)-based method for the detection of food-borne pathogens-Horizontal method for the detection of Shiga toxin-producing Escherichia coli (STEC) and the determination of O157, O111, O26, O103 and O145 serogroups. International Organization for Standardization (ISO), Geneva, Switzerland.

Melton-Celsa, A., K. Mohawk, L. Teel, and A. O'Brien. 2012. Pathogenesis of Shiga-toxin producing Escherichia coli. Pages 67-103 in Ricin and Shiga Toxins. N. Mantis, ed. Springer, Berlin, Germany.

Ribot, E. M., M. A. Fair, R. Gautom, D. N. Cameron, S. B. Hunter, B. Swaminathan, and T. J. Barrett. 2006. Standardization of pulsed- 
field gel electrophoresis protocols for the subtyping of Escherichia coli O157:H7, Salmonella, and Shigella for PulseNet. Foodborne Pathog. Dis. 3:59-67.

Scheutz, F., L. D. Teel, L. Beutin, D. Pierard, G. Buvens, H. Karch, A. Mellmann, A. Caprioli, R. Tozzoli, S. Morabito, N. A. Strockbine, A. R. Melton-Celsa, M. Sanchez, S. Persson, and A. D. O'Brien. 2012. Multicenter evaluation of a sequence-based protocol for subtyping Shiga toxins and standardizing stx nomenclature. J. Clin. Microbiol. 50:2951-2963.

Schroeder, C. M., J. Meng, S. Zhao, C. DebRoy, J. Torcolini, C. Zhao, P. F. McDermott, D. D. Wagner, R. D. Walker, and D. G. White. 2002. Antimicrobial resistance of Escherichia coli O26, O103,
O111, O128, and O145 from animals and humans. Emerg. Infect. Dis. 8:1409-1414.

Spano, G., E. Goffredo, L. Beneduce, D. Tarantino, A. Dupuy, and S. Massa. 2003. Fate of Escherichia coli O157:H7 during the manufacture of Mozzarella cheese. Lett. Appl. Microbiol. 36:73-76.

Trevisani, M., R. Mancusi, G. Delle Donne, C. Bacci, L. Bassi, and S. Bonardi. 2014a. Detection of Shiga toxin (Stx)-producing Escherichia coli (STEC) in bovine dairy herds in Northern Italy. Int. J. Food Microbiol. 184:45-49.

Trevisani, M., R. Mancusi, and A. Valero. 2014b. Thermal inactivation kinetics of Shiga toxin-producing Escherichia coli in buffalo Mozzarella curd. J. Dairy Sci. 97:642-650. 